\title{
Commitment of Newcomers and Old-timers to Online Health Support Communities
}

\author{
Diyi Yang \\ Carnegie Mellon University \\ diyiy@cs.cmu.edu
}

\author{
Robert Kraut \\ Carnegie Mellon University \\ robert.kraut@cmu.edu
}

\author{
John M. Levine \\ University of Pittsburgh \\ jml@pitt.edu
}

\begin{abstract}
For online communities to be successful, they must retain an adequate number of members who contribute to the community. The amount and type of communication members receive can play an important role in generating and sustaining members' commitment to it. However, the communication that members find valuable may change with their tenure in the community. This paper examines how the communication members receive in an health-support community influences their commitment and how this influence changes with their tenure in the community. Commitment was operationalized with three measures: self-reported attachment, continued participation in the community, and responding to others. Results show that receiving communication was generally associated with increased commitment across the three measures, with its impact increasing with members' tenure. However, the average amount of informational and emotional support members received per message was associated with decreased commitment. Results have implications for interventions to encourage members' commitment to their communities throughout their history in the community.
\end{abstract}

\section{ACM Classification Keywords}

H.5.3. Information Interfaces and Presentation: Group and Organization Interfaces-Computer-supported cooperative work, Asynchronous interaction, Collaborative computing, Web-based interaction, Evaluation/methodology

\section{Author Keywords}

Commitment; Communication; Group Socialization; Online Health Support Communities; Social Support

\section{INTRODUCTION}

Millions of people use the Internet daily to participate in online communities. For example, they exchange information in technical and health support groups, meet new people and maintain personal relationships on dating and social networking sites, work together for collective action on platforms such as Wikipedia, create and consume entertainment on blogs and YouTube, and exchange social support in online health support

Permission to make digital or hard copies of all or part of this work for personal or classroom use is granted without fee provided that copies are not made or distributed for profit or commercial advantage and that copies bear this notice and the full citation on the first page. Copyrights for components of this work owned by others than ACM must be honored. Abstracting with credit is permitted. To copy otherwise, or republish, to post on servers or to redistribute to lists, requires prior specific permission and/or a fee. Request permissions from Permissions@ acm.org.

CHI 2017, May 06-11, 2017, Denver, CO, USA

2017 ACM. ISBN 978-1-4503-4655-9/17/05 . \$15.00

DOI: http://dx.doi.org/10.1145/3025453.3026008 communities such as the American Cancer Society's Cancer Survivor Network. Our work deals with the exchange of social support.

To survive and prosper, online communities must recruit, socialize and retain successive generations of new members. If a community does not replace members who leave, it will eventually die. This is because members are critical resources in online communities; they share information, provide help, and form social ties with others. New members may be especially valuable because they are often a source of new ideas, diversity, and innovation for the community [27]. In contrast, higher tenured members of online communities may serve other important roles [42]. For example, they often provide leadership and set the direction of the community, mentor less experienced members, and promulgate and enforce community norms [22, 26, 61].

However, evidence from a wide variety of online communities indicates that a substantial number of new members drop out before they could plausibly receive many benefits from the community or contribute benefits to others [2, 21, 59]. Moreover, higher tenured members can drop out as well, and their loss may have an especially large impact on the community. Thus, in order to understand the health of online communities, it is necessary to understand the factors that influence both new and more established members' commitment to them. Commitment is a key determinant of members' continued participation in the community, which in turn affects their likelihood of contributing back to it.

In this work, we examine how the communication that members of an online cancer community receive affects their commitment. We extend previous research by showing how members' tenure in the community affects their responses to communication. Although others have investigated commitment to offline and online organizations, little research in either setting has examined how the factors influencing commitment change with participants' tenure in the community. We use Levine and Moreland's model of group socialization to theoretically frame our research [29, 31]. According to this model, members engage in an evaluation process to determine how well the group can satisfy their needs. In so doing, they consider how rewarding the group has been in the past, how rewarding it currently is, and how rewarding it is likely to be in the future. The outcome of this evaluation process determines members' commitment to the group, which in turn affects the likelihood that they will remain in it and expend effort to achieve collective goals. 
The specific rewards that determine members' commitment vary across groups and depend on the functions that groups serve for their members. Across many types of online communities, and especially in health support groups, the exchange of informational and emotional support is a critical function [46]. In the current research, we focus on the relationship between members' commitment to health support groups and their exchange of these forms of support $[6,9,48]$.

The Role of Group Tenure: Newcomers and Old-timers

The rewards, or resources, that determine commitment are likely to be influenced by members' tenure in the group.

\section{Assessing Fit}

New and higher tenured members have had different experiences, which are likely to shape the group activities they find most rewarding [51]. For example, early in their history in a group, members have high uncertainty about the type of people who are members, the group's norms, how they fit into the group, and the benefits they will gain from participating in it. Therefore, group activities that help them reduce their uncertainty, such as receiving direct social support in response to their requests, are likely to increase their commitment to the community [5]. To reduce this uncertainty, newcomers often observe and question old-timers and generally seek information. Much research on newcomer socialization has demonstrated the importance of information seeking and uncertainty reduction in increasing newcomers' commitment [19], their resistance to turnover [8] and their willingness to go beyond their job descriptions through voluntary organizational citizenship behavior [30]. By definition, longer-term members have participated in the group longer and hence have accumulated more group-relevant knowledge than those with less tenure.

Most research on the way that information seeking influences the socialization of newcomers has been conducted in offline contexts, typically business organizations $[4,8,50]$. Although this research is relevant to socialization in online communities, there are potentially important differences between the two contexts. Because it is much easier for newcomers to leave one online community for another than it is for new employees to leave one company for another, certain types of uncertainty reduction may be even more important for online than for offline newcomers. While new employees often try to reduce uncertainty about their roles and how they fit into a company, newcomers in online communities are often trying to answer a more fundamental question, namely whether the community is worth their time and effort in the first place. As a result, online newcomers may be especially motivated to obtain communityrelevant information and leave the community if they fail to get it.

\section{Reducing Uncertainty}

Members can assess their fit by posting messages that seek replies from other members, and they are likely to interpret the number of replies and their quality as indicators of the value the community will have for them. In addition, they can use these posts to explicitly seek resources the community has to offer. Here we distinguish between informational support and emotional support, which prior research indicates are the major resources that people seek in health support groups [47, 48, 46]. Informational support is the information, advice, referrals or knowledge that people exchange, whereas emotional support refers to the expressions of caring, concern, reassurance, or empathy people receive from others.

There are reasons to think that newcomers may disproportionately seek informational support over emotional support. In part this is because they often visit and join health support groups during the early stage of their disease, when they are still trying to make sense of it, to obtain disease-relevant information. For example, in the American Cancer Society's Cancer Support Network (CSN), which is the site for our current research, the overwhelming majority of initial visitors come to the site via a Google search, suggesting that they are looking for information.

In addition, early in their careers in the support community, newcomers may disproportionately seek informational support because they have not yet built up the social capital necessary to effectively seek emotional support. Seeking information is a rather impersonal transaction in that neither seekers nor providers of information need to reveal much about themselves for information exchange to be successful. Thus, seeking informational support may be particularly appealing to newcomers because it does not depend upon personal ties with other community members.

Hypothesis 1. Members of lower tenure in a community will seek more support than will members of higher tenure by posting more messages to start communication threads, and these messages will focus on eliciting informational rather than emotional support.

\section{Effects of Communication}

As suggested above, interpersonal communication is a major route through which people reduce uncertainty about the nature of an online community and receive the benefits associated with membership. For example, when they first enter a community they may "lurk" (i.e., observe without posting) to see what others are doing to get a better sense of what the community is about and its fit to their needs [41]. They may also probe the community more proactively, through various information seeking behaviors [1,36, 37], interacting with others in the community to reduce their uncertainty.

Over and above uncertainty reduction, communication is also the major route through which community members reap the other rewards that communities have to offer. People join online communities for many purposes, and accomplishing them is crucial for their commitment. For example, cancer patients may join an online support group to receive useful information, to compare their situation to that of others, to strengthen their social identity as survivors, to experience enjoyable social interactions or to exchange emotional support [46]. Online communication is central to accomplishing all of these goals. For example, research suggests that members' frequency of communication with others in online communities is a major determinant of the extent to which they build connections with others [34]. Increased communication among members allows people to form social bonds and enhances trust, and as their 
frequency of communication increases, their liking for each other increases.

Even mere exposure to others' communication may encourage people to remain active in the group, strengthen their relationships with other members, and enhance their commitment to the group. Slater et al. [54] found that peoples' commitment and group performance increased when they had a sense of being with the other people in a virtual environment, suggesting that mere awareness of others' communication keeps them engaged in online communities.

Communication within a community helps people identify with the community as a whole and build ties with its members, both of which increase members' commitment [51, 45]. Although prior theoretical analyses have distinguished between identity-based attachment to a group as a whole and bond-based attachment to its members[43], empirical research demonstrates that these two pathways to commitment are highly correlated and in practice are difficult to distinguish. For example, experimental manipulations designed to differentially increase identity or bond-based attachment tend to increase both and the consequences of bond-based and identitybased attachment are similar [56, 44, 45]. For this reason, we combine them in the current research.

In the health support communities, members use communication to discuss their disease, talk about their problems, and exchange informational or emotional support [11]. Because members' beliefs that they can achieve these goals are a major determinant of their commitment to the community, online communication should increase the commitment of both lowerand higher-tenure community members.

Hypothesis 2. Receiving more communication and support from an online community will increase recipients' commitment to the community for both higher tenured and lower tenured members.

Notwithstanding Hypothesis 2, it is possible that engaging in communication will be differentially effective in increasing the commitment of higher- and lower-tenured members. Theories of diminishing marginal utility and selective retention are consistent with this, but suggest two alternative hypotheses.

\section{Diminishing Marginal Utility}

The principle of diminishing marginal utility [24] implies that engaging in communication will have a larger effect on the commitment of lower-tenured than higher-tenured members. This is because the marginal utility of each new unit of communication should vary inversely with the amount of communication members have previously experienced. Thus, lower-tenured members should find communication more rewarding than should higher-tenured members.

The marginal utility that people receive from money [23], consumer goods, and information all follow the law of diminishing returns. People seem to derive less value per unit of each of these resources as they get more of them. For example, scientists gain fewer new ideas per personal relationship the more relationships they have [33], and Facebook users gain less social capital benefits per friend the more Facebook friends they have [15]. So too, it is plausible to predict that people will receive less benefit from exchanges in the community the longer they have been in it.

In particular, each exchange they experience should be less helpful in reducing their uncertainty about the nature of the community. In addition, they should receive fewer informational and emotional support benefits the longer they have been in the community because many questions and comments posted to the community address similar topics. While reading them might be valuable to new members who have not yet been exposed to community thinking on a topic, higher tenured members are likely to have previously seen similar content. Similarly, the emotional support members receive from a particular reply should be less valuable when they have already received support from other community members in the past. To the extent that benefits that members receive from communication influence their commitment to the community, then according to theories of diminishing marginal utility, communication should have greater positive impact on commitment for lower tenured than for higher tenured ones.

Hypothesis 3A. Communication should increase participants' commitment to the community more for members of lower tenure.

\section{Reinforcement Value of Participation}

The type of rewards that determine participants' commitment can change as a function of their tenure in the community. For example, in many information-sharing communities, including health support groups, newcomers may be drawn to the community by the motivation to acquire information about their particular problem, and they can arrive at the site either through Internet search services or direct navigation to the community's website. In such cases, they can obtain useful information by passively reading messages that others have posted or by explicitly asking questions. In contrast, later in their tenure, when they have explored most of the information the community has to offer, they may lose interest in receiving such support.

Differential retention is another reason why tenure may influence the rewards that determine participants' commitment. The theory of Person-Environment fit [10] and the AttractionSelection-Attribution model of organizational function [52] imply that people are more likely to stay in a organization when it matches their attributes and needs. Newcomers generally sample online communities because they expect the community will be able to satisfy their needs. However, because they often have little information about the community before entering, in many cases their preliminary assessments of the community are wrong and they discover that it does not satisfy their needs. In such cases, dissatisfied newcomers often leave soon after joining. One consequence of this process is that, on average, members who remain in a community will like what it has to offer more than will people with less tenure, at least some of whom are likely to become disenchanted and leave. As a result, various aspects of the community will generally be more rewarding for high tenured members than for newcomers and will cause high tenured members to have higher commitment to the community. 
This mismatch between expectations and experience can partly explain why newcomers have a much higher dropout rate than do higher tenured members [2]. Moreover, according to the attraction-selection-attrition model, if newcomers leave because they fail to find interactions in the community valuable, the satisfied people remaining produce a community that is both more positive and homogeneous in terms of members' satisfaction. If this dynamic in fact occurs, then communication episodes will have more reinforcement value for higher tenured members than for less experienced ones.

Hypothesis 3B. Communication should increase participants' commitment to the community more for members of higher tenure.

\section{Differential Preference for Social Support}

Hypotheses 3A and 3B are based on the premise that receiving communication-based benefits from a group changes participants' commitment, with $\mathrm{H} 3 \mathrm{~A}$ arguing that the benefits will be larger for newcomers while $\mathrm{H} 3 \mathrm{~B}$ argues that the effects will be larger for more experienced members. However, the nature of the resources that influence commitment may also change over time, as members with different needs differentially drop out or stay.

The reasoning behind $\mathrm{H} 1$ - that newcomers will disproportionately seek informational support - also suggests that they will benefit more from informational than from emotional support. In contrast, higher tenured people in the community should benefit more from the exchange of emotional support, either because those who need informational support have dropped out after acquiring the information they sought or because longer-term members desire to exchange emotional support to enhance and exploit their personal relationships. Seeking and receiving emotional support often lead to personal connections between seekers and providers. Even Weizenbaum's classic Eliza computer program emulating a Rogerian therapist [60] promoted a personal connection between human recipients and the software agent, at least until the software's lack of language understanding become apparent [60]. Other research suggests that, not only does receiving emotional support lead to interpersonal ties, but seeking it may as well. In order to elicit emotional support, people reveal intimate details about their lives, for example negative thoughts and feelings about their disease [59]. This self-disclosure, in turn, should make the listener like the discloser more [18, 43]. Moreover, since personal ties take time to grow, they are more likely to occur for higher tenured members than for newcomers. To the extent that people with more experience have these personal interactions to a greater extent than do newcomers, emotional support should differentially increase their commitment to the group.

Hypothesis 4. The exchange of informational support will differentially increase commitment for lower tenured members of the community, while the exchange of emotional support will differentially increase commitment for higher tenured members.

\section{METHODS}

As we argued above, communication should affect the commitment of newcomers and higher tenured community members differently. Few studies have provided relevant data. We address this question in the context of online health support communities, examining (a) how communication changes people's commitment to the group and (b) the extent to which this change varies as a function of people's tenure in the group.

\section{The Cancer Survivors' Network}

Our analyses are conducted in the discussion boards of the American Cancer Society's Cancer Survivor Network $\left(\mathrm{CSN}^{1}\right)$. CSN is the largest online support community for people suffering from cancer and their caregivers. According to Google Analytics, approximately 3.5 million people visited the site from September 2013 to October 2014, with 67\% being new visitors and 33\% returning. The site registered over 11 million pageviews distributed over 5 million sessions. Visitors mainly came from English speaking countries, primarily United States.

\section{Dataset}

Our collaboration with the American Cancer Society provided us access to all public posts and comments, along with profile information for users registered between Dec 2002 and Feb 2015. During this period, there were a total of 48,317 registered users who exchanged 1,073,020 messages belonging to 131,237 threads. In addition to this longitudinal data collected by the site's server logs, we also collected three waves of questionnaires. The questionnaire was initially sent by email in January 2014 to all of CSN's 83,602 registered members, including many who had not logged into the site in the previous two years. Twenty percent of the emails were undeliverable. 5,605 members responded by filling out at least one questionnaire (8.4\% of delivered invitations). Among other topics, the respondents reported on their motives for using the support group and their attachment to it. In addition, we interviewed 12 CSN users, whose responses provided context for the quantitative results we will report.

\section{Measures \\ Tenure in the support group. Most previous research on or- ganizational socialization has dichotomized organizational tenure into newcomers and old-timers, based on their time since joining [49]. For example, many studies define newcom- ers as members who have been in the organization for less than 2 or 3 years [20,29]. However, the process of organizational socialization is a likely to be continuous, with no clear thresh- old separating newcomers from old-timers [14]. Therefore, in this research, we use a continuous measure of a person's tenure in the community based on the number of months since that person registered. Although our analyses use a continu- ous measure of tenure, for simplicity, we sometimes describe members of lower tenure as relative newcomers and those with more tenure as relative old-timers.}

Maximum tenure. Prior research demonstrates that people who ultimately stay in a community for a long period and become core members act differently from those who drop out quickly even on their first day [39, 40]. Therefore, in all analyses reported below, except for survival analysis, we

\footnotetext{
${ }^{1}$ http: //csn. cancer.org
} 
control for this individual difference by including a measure of maximum tenure, which is the total number of months that a user remained active in the community (i.e., the months from registration to last post).

Seeking social support. Most research on the exchange of support in health support groups has used self-report measures from participants or a relatively small set of messages handcoded by the researchers [13, 48, 53]. Recently, automatic text analysis techniques of conversations has enabled largescale analysis $[57,58]$. Using procedures similar to those developed by Wang et al [58], we first built machine learning models to automatically identify the extent to which messages exchanged in the discussion forums contained emotional or informational support. The machine learning regression models map a set of linguistic features, as described in detail in [58], to a set of output categories, indicating how much informational support a message conveys, how much emotional support a message contains as well as how much informational and emotional support a thread-starting message is seeking. Four trained nursing students rated a sample of 1000 messages threads for how much informational and emotional support the thread-starting message was seeking, and how much informational and emotional support the first response to the thread-starting message conveys. The human judges were very reliable with Cronbach's alphas of $0.91,0.83,0.92$ and 0.92, for seeking informational support, seeking emotional support, receiving informational support and receiving emotional support respectively. The machine learning models were highly correlated with the average of the human judgments, with Pearson Correlation $r=0.80,0.73,0.83,0.81$ for seeking informational support, seeking emotional support, receiving informational support and receiving emotional support respectively. Given the adequate validity of these models, we then applied them to estimate the support exchanged in the 104,343 thread-starting messages and 922,402 comments in the CSN discussion boards.

We operationalized support seeking with three variables: (1) seek count: the number of thread-starting messages a member posted in a time period; (2) seek informational support: the average amount of informational support per thread sought by a user in each thread-starting message; (3) seek emotional support: the average amount of emotional support per thread sought by a user in each thread-starting message.

Receiving social support. We considered receiving support as the support a member had received in response to the threads he or she started. We operationalized it using three variables: (1) comments received: the number of comments members received to their own thread-starting messages; (2) informational support received: the average amount of informational support contained in responses to users' own thread-starting posts; (3) emotional support received: the average emotional support in responses to users' own thread-starting posts.

Commitment. We operationalized commitment using three correlated metrics: members' self-reported attachment to the community $[43,45]$, the length of time they continued to participate in the community and their willingness to help others in the community by providing them social support.
Self-reported attachment refers to responses to a self-report survey about people's feelings towards their group and its members. The survey included questions to measure attachment to the group as a whole, which were adapted from Mowday et al.'s organizational commitment scale [38] and Prentice et al.'s common-identity scale [43], (e.g., "I am glad to be a member of CSN"; "CSN has become an important part of my life"). It also included questions adapted from Prentice et al.'s common-bond measure of attachment (e.g., "I feel very close to some of the people I've met on CSN"; "CSN members have influenced my thoughts and behaviors"). Because the selfreported identity attachment and bond attachment scales correlated $(\mathrm{r}=0.67)$, we combined them to create a Self-reported Attachment score. This 9-item scale was highly reliable, with an internal consistency measured by Cronbach's alpha of 0.89 and test-retest reliability over approximately six-months of 0.74 .

Behavioral length of participation consists of the number of months between users' first post during a time period to their last post or the end of our data collection period, whichever comes first.

Willingness to help others. We measured willingness to help others as the number of responses people made to others' thread-starting posts.

The three forms of attachment in fact are moderately correlated. The Pearson correlation between self-reported attachment and length of participation is 0.35 , between self-reported attachment and the number of responses to others is 0.27 , and between behavioral length of participation and the number of responses to others is 0.47 . The correlation among these measures justifies including them in parallel analyses.

Motivations for using the support group. The self-report questionnaire included several 4-item scales in which respondents described their reasons for using CSN. The three most relevant to the present paper are using CSN (1) To get informational support (e.g., "To get information about the cancer I'm dealing with."), (2) To get emotional support (e.g., "To be comforted by others ... who have been there." ) and (3) To provide support to others (e.g., "To share my experiences with cancer."). These scales were internally consistent, with Chronbach alphas of .87, .94 and .96 respectively. They had modest test-retest reliability over 6-month intervals of .52, .62 and .62 respectively.

\section{ANALYSES AND RESULTS}

We tested our hypotheses via four analyses as follows. Analysis 1 investigates $\mathrm{H} 1$, the shifts in the support that members seek with tenure. Analyses 2, 3 and 4 examine $\mathrm{H} 2, \mathrm{H} 3$ and $\mathrm{H} 4$, the effects of receiving communication and of experience on commitment, using alternate measures of commitment. Analyses 2, 3 and 4 use panel data and lagged dependent variable analyses to examine how the communication received in one time period predicts changes in commitment at a later period. This type of data analysis mitigates many problems in inferring causation from correlational data [25, 7], by controlling for individual differences with each individual observed multiple times, and by providing information on the temporal ordering of the relationships. Note that due to limited observations 


\begin{tabular}{r|c|c|c|c}
\hline & Model 1 & Model 2 & Model 3 & Model 4 \\
\hline Dependent Variables & Seek count & Seek informational support & Seek emotional support & Seek info support ratio \\
\hline Intercept & $0.182^{* * *}$ & $0.138^{* * *}$ & $0.223^{* * *}$ & -0.009 \\
\hline Has profile & $-0.157^{* * *}$ & 0.030 & $-0.196^{* * *}$ & 0.009 \\
\hline Maximum tenure & $-0.003^{* * *}$ & $-0.005^{* * *}$ & $-0.001^{*}$ & 0.001 \\
\hline Tenure & $0.102^{* * *}$ & $-0.073^{* * *}$ & $-0.187^{* * *}$ & -0.013 \\
\hline Tenure x tenure & $0.045^{* * *}$ & $0.027^{* * *}$ & 0.001 & 0.005 \\
\hline R Squared & 0.011 & 0.048 & 0.125 & 0.000 \\
\hline
\end{tabular}

Table 1. Regression coefficients of tenure. Number of users $=12,908$. Number of observations $=25,243$. Here, $\mathbf{p}<0.001$ : $^{* * *} ; \mathbf{p}<0.01 * * ; p<0.05 *$.

of self-reported attachment measures, we do not test $\mathrm{H} 4$ in Analysis 2.

\section{Analysis 1: Seeking Support}

H1 predicted that seeking support, and especially informational support, would decline with tenure. Our first test correlated members' self-reported motives for using CSN with their tenure in the community (i.e., the number of months they had been a member of CSN at the time of completing a survey). To insure that respondents were reporting on their motives for relatively recent participation in CSN, we restricted the analysis to those whose last login to the site was within six months of completing their first questionnaire.

Seeking informational support as a motive for using CSN declined slightly with tenure $(\mathrm{r}(1227)=-0.024, \mathrm{p}=0.386)$, while seeking emotional support as a motive increased with tenure $(\mathrm{r}(1227)=0.081, \mathrm{p}=0.005)$. In addition, giving help to others as a motive increased with tenure $(\mathrm{r}(1227)=0.187, \mathrm{p}<0.001)$. While all the effect sizes were small, they differed reliably from each other, with the correlation of tenure with giving help greater than its correlation with getting emotional support $(\mathrm{z}=4.50, \mathrm{p}<0.001)$, which in turn was greater than its correlation with seeking informational support $(\mathrm{z}=3.84, \mathrm{p}<0.001)$.

To further explore the H1 predictions, Figure 1 shows the support-seeking behaviors over time, using longitudinal data. As predicted, seeking informational and emotional support per message declined with tenure. However, the figure shows that the number of thread-starting messages users posted does not monotonically increase or decrease with their tenure in the community.

To more systematically test $\mathrm{H} 1$, we conducted multi-level, random-effects, linear regression to predict how the number of thread-starting messages and the average informational and emotional support sought per message during a month varied with members' tenure, with month nested with members. To guard against the possibility that the effects of tenure reflect differences among people who drop out quickly and those who remain, these analyses controlled for members' maximum tenure and whether they created a profile when they registered. As a robustness check, we also conducted a fixedeffects regression analysis (not reported in this paper), which held constant all stable individual differences, including unmeasured ones. The results of the fixed effects regression are consistent with results reported in Table 1.

(1) Model 1 uses the number of thread-starting messages members posted as the dependent variable. Although the linear trend for tenure suggests that the number of support-seeking messages increases with tenure, the quadratic trend and Figure 1 show that number of support-seeking messages declines with tenure for approximately 17 months before increasing. (2) Models 2 and 3 in Table 1 show that the degree to which these messages sought informational and emotional support declined significantly with tenure, confirming the initial part of $\mathrm{H} 1$ and consistent with the first part of $\mathrm{H} 1$.

However, the second part of H1 was also not supported. Seeking informational support did not decline faster than seeking emotional support. Indeed Figure 1 and the coefficients for tenure in Model 2 (Seek informational support) and Model 3 (Seek emotional support) suggest that the decline is faster for informational support. However, Model 4 explicitly tests differential decline. The dependent variable is the ratio of seeking informational support to the sum of seeking emotional support plus seeking informational support. This analysis shows that the type of support sought did not reliably change with tenure.

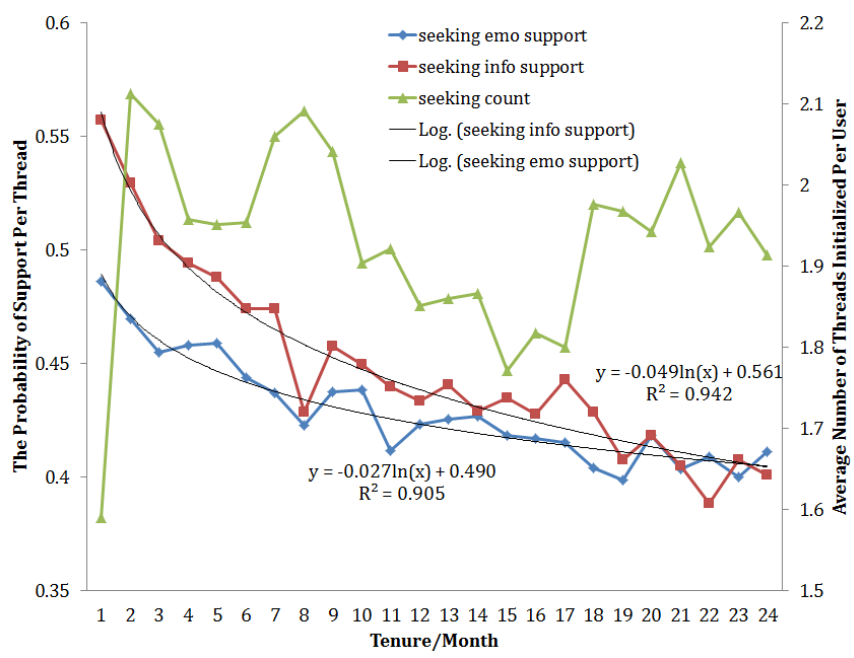

Figure 1. Seeking support over time.

\section{Analysis 2: Self-reported Commitment}

Analysis 2 examines how members' self-reported commitment to CSN changes with their tenure and the amount and type of support they received. Table 2 shows the results of hierarchical linear regressions predicting respondents' self-reported commitment to CSN from their tenure when they completed the questionnaire (i.e., the number of months since they registered for CSN), the amount of communication they received from 


\begin{tabular}{r|c|c}
\hline Predictors & Model 1 & Model 2 \\
\hline Intercept & -0.072 & -0.073 \\
\hline Has profile & 0.048 & 0.047 \\
\hline Age & 0.046 & 0.046 \\
\hline Household income & -0.009 & -0.01 \\
\hline Highest education & $-0.061^{* *}$ & $-0.060^{* *}$ \\
\hline Cancer stage & 0.041 & 0.040 \\
\hline Marital status & 0.035 & 0.036 \\
\hline Gender & 0.027 & 0.028 \\
\hline Employment & 0.032 & 0.031 \\
\hline Tenceived real world support & -0.031 & -0.031 \\
\hline Comments received & $0.094^{* * *}$ & $0.094 * * *$ \\
\hline Tenure x Comments received & & -0.018 \\
\hline R Squared & 0.575 & 0.575 \\
\hline Supported Hypotheses & $\mathrm{H} 2$ & Not H3 \\
\hline
\end{tabular}

Table 2. Regression coefficients of communication on self-reported commitment. Number of users $=790$. Number of observations $=1,101$. p $<0.001$ :***; $^{*}<0.01$ :**; $^{*}<0.05$ :*. $^{*}$.

others previously (i.e., comments received) and a set of control variables: age, gender, marital status, highest education level, household income, cancer stage, employment status, and prior perceived real world support. By including self-reported attachment from the prior questionnaire as a predictor, this analysis tests effects on changes in commitment [12].

The analyses is based on 790 respondents who completed at least two questionnaires and participated in forum discussions between them. Because 311 participants completed three questionnaires and therefore had two records that included a current and prior commitment score, the analysis uses a hierarchical linear model with questionnaire nested within respondent and respondent as a random effect to deal with non-independence in the data.

Model 1 describes the main effects of the control variables, communication and tenure on self-reported commitment. It shows that receiving comments from others is associated with increases in people's self-reported commitment to CSN. This result supports $\mathrm{H} 2$ and suggests that direct communication with others makes people feel more connected to other members and the group as a whole.

Model 2 adds the interaction between people's tenure when they completed a questionnaire and the number of comments they received. However, the interaction effect is not significant and supports neither H3A nor H3B. Overall, Analysis 2 supports $\mathrm{H} 2$, and not $\mathrm{H} 3 \mathrm{~A}$ or $\mathrm{H} 3 \mathrm{~B}$. The lack of an interaction with tenure may occur because respondents who answered at least two questionnaire were mostly higher tenured members, with a mean tenure on the site of 33 months; only $7 \%$ of them had registered for CSN within six month of completing their first questionnaire.

\section{Analysis 3: Length of Participation}

Analysis 3 uses survival analysis to assess how tenure and the amount and type of support members receive jointly influence commitment to the community, in this case defined as the length of their subsequent participation in CSN. Survival analysis is a type of regression model for estimating influences on the time to an event of interest, which in our context is dropping out of CSN. Survival analysis corrects the biased estimates that would result from OLS regression because of censoring (i.e., some people have not yet left the group at the time of analysis). We used the statistical software package Stata [55] and assumed a Weibull distribution of survival times.

The analysis examines how the amount and type of communication influence when a cancer patient leaves the CSN community or, conversely, how long they continue to participate, after receiving comments from the community. In Table 3, the influence of the explanatory variables is represented as Hazard Ratios (HR), which indicates the relative likelihood of participants' leaving the group based on the number comments they received during a month and type of support they received that month. The unit of analysis is the participant-month, with time-varying independent variables. As a control variable, the analysis included whether the member had a profile, which is a signal of his/her commitment to the community when he/she registered.

The analysis includes 52,076 CSN members who had posted at least once. The timestamp of a user's first activity (e.g. creating a post, sending a private message or browsing the website) is considered as his/her starting date for participating in CSN, and the date of the last activity is the end of participation unless it was the last month before the end of data collection, in which case we consider the end of his/her participation to be censored or unknown The dependent variable is Drop. A user is defined as dropping out from the community if he/she has not made any posts within three months of his/her last post. By this criterion, users can leave the group and rejoin it multiple times.

Results of the survival analysis are shown in Table 3 . Since the continuous explanatory variables were standardized, the HR is the predicted change in the probability of dropout from CSN for a standard deviation increase in the predictor. Model 1 reports the main effects of communication with the group and content of support exchanges. The HR for tenure indicates that people who had been in the community a standard deviation longer than average were $56 \%(100 *(1-0.436))$ more likely to continue in the community. The HR for comments received means that members who received a standard deviation more comments in a month stayed $17 \%(100 *(1-0.826))$ longer than those who received the average number of comments, supporting $\mathrm{H} 2$. Model 2 adds the interaction between tenure and comments received. Among those receiving a standard deviation more comments than average, higher tenured members were an additional $5 \%$ more likely to stay in the community than those with less tenure, supporting H3B.

Model 3 adds the predictors for type of support. Users who received a standard deviation more informational support per message were $15 \%$ more likely to leave the community and those who received a standard deviation more emotional support per message were $10 \%$ more likely to leave, contradicting $\mathrm{H} 2$. Model 4 adds the interaction between tenure and the 


\begin{tabular}{r|c|c|c|c}
\hline Predictors & Model 1 & Model 2 & Model 3 & Model 4 \\
\hline Has profile & $0.717^{* * *}$ & $0.719^{* * *}$ & $0.740^{* * *}$ & $0.739^{* * *}$ \\
\hline Tenure & $0.440^{* * *}$ & $0.436^{* * *}$ & $0.440^{* * *}$ & $0.434^{* * *}$ \\
\hline Comments received & $0.826^{* * *}$ & $0.811^{* * *}$ & $0.652^{* * *}$ & $0.616^{* * *}$ \\
\hline Informational support received & & & $1.149^{* * *}$ & $1.187^{* * *}$ \\
\hline Emotional support received & & & $1.107^{* * *}$ & $1.139^{* * *}$ \\
\hline Comments received x Tenure & & $0.949^{* * *}$ & & $0.873^{* * *}$ \\
\hline Informational support received x Tenure & & & & $1.078^{* * *}$ \\
\hline Emotional support received x Tenure & & & & $1.044^{* * *}$ \\
\hline Supported Hypotheses & $\mathrm{H} 2$ & $\mathrm{H} 3 \mathrm{~B}$ & $\mathrm{Not} \mathrm{H} 2$ & $\mathrm{H} 3 \mathrm{~A} ; \mathrm{Not} \mathrm{H} 4$ \\
\hline
\end{tabular}

Table 3. Survival Analysis predicting how long members continue to participate in the community. Note cell entries are hazard ratios associated with a unit increase in an independent variable. Here, $\mathbf{p}<0.001$ : $* * * ; p<0.01 * * ; p<0.05^{*}$. Number of users $=52,076$. Number of observations (user-month records) $=\mathbf{1 1 5 , 4 0 4}$

communication related variables. Compared to lower tenured users, higher tenured users who received one standard deviation more informational support were an additional $8 \%\left(-28 \%{ }^{2}\right.$ $-(1-1.187) \times 100 \%)$ less likely to stay in the community. These results support $\mathrm{H} 3 \mathrm{~A}$ and disconfirm $\mathrm{H} 4$ by demonstrating that both kinds of support make lower tenured members stay longer in the community. Figure 2 illustrates these results graphically.

Survival Bias: Because cancer patients may fail to return to CSN because they died, we conducted a robustness check by rerunning Analysis 3 for three common cancer types prostate, breast and lung - that vary widely in 5-year survival rates (from $99 \%$ (prostate) to $18 \%$ (lung)). We found similar results for all three cancer types, which suggests that death is not a compelling explanation for dropout.

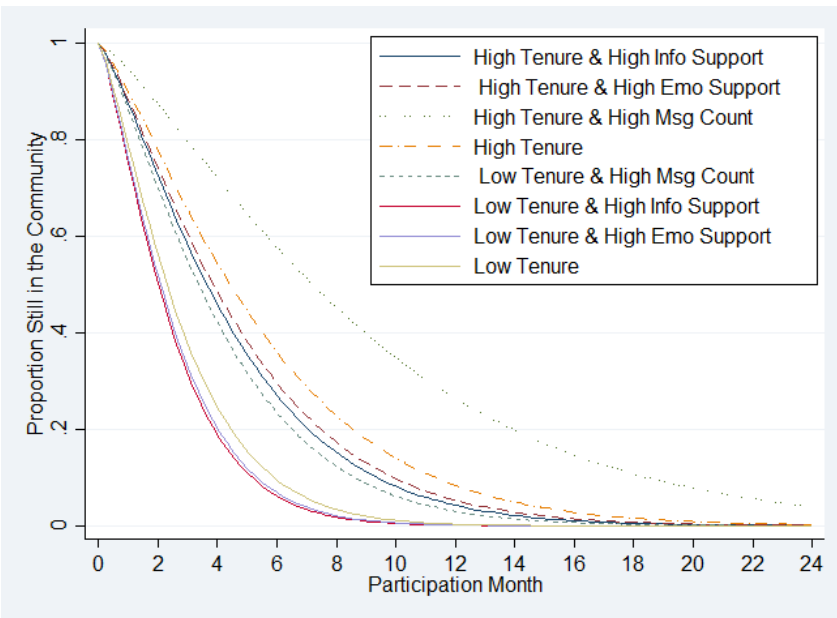

Figure 2. Survival curves for members of different tenure and communication frequency

\section{Analysis 4: Volunteering to Help Others}

As a third test of how tenure and participation in an online community jointly influence commitment, we used hierarchical, random-effects regression to model how the amount and content of comments participants received in a month were associated the number of comments they provided to others in the next month. Here, we treat comments participants provide as a proxy for their willingness to help others. The independent

$\overline{2}(1-\exp (\log (1.187)+\log (1.078))) \times 100 \%=-28 \%$ variables-comments received and informational or emotional support received-are averaged across all messages exchanged in the current month and then are all standardized with a mean of zero and a standard deviation of one. The control variables in the analysis include the number of comments provided to others in the previous month (Previous provided comments), the number of threads a user initialized in the previous month (Previous initialized threads), whether a user created a profile (Has profile), and the maximum tenure for this user (Max tenure).

Model 1 in Table 4 describes the main effects of receiving comments on users' willingness to help others. The coefficient for maximum tenure $(\beta=0.256)$ shows that members who ultimately stay in the community longer provide more comments to others. However, holding constant this individual difference, the coefficient for tenure $(\beta=-0.051)$ shows that the willingness to help others declines month-to-month. A robustness check using fixed-effects regression indicates that this decline in providing comments with time holds, even if maximum tenure is not included in the model $(\beta=-0.426)$. In addition, participants receiving more comments in the prior month did not provide more comments to others. This result that does not support $\mathrm{H} 2$, and indeed, calls into question the assumption that reciprocity of contributions is universal in online communities [16].

The interaction between tenure and comments received in Model 2 indicates that when users with mean tenure receive comments they offer fewer in return $(\beta=-0.027)$. In contrast, when users with above average tenure receive comments, they offer more in return $(\beta=0.046)$, supporting H3B.

Model 3 adds the effects of type of comments received. Receiving a standard deviation more informational or emotional support was associated with providing others with fewer comments, disconfirming $\mathrm{H} 2$.

Model 4 adds the interactions between tenure and the informational and emotional support received in a month. It shows that receiving emotional support was associated with offering less help to others for users with more tenure, but not for users with average tenure $(\beta=-0.022)$, supporting H3A. No interaction effect is found for receiving informational support.

Overall, Analysis 4 demonstrates that receiving comments seems to increase commitment for higher tenured members, 


\begin{tabular}{r|c|c|c|c}
\hline Predictors & Model 1 & Model 2 & Model 3 & Model 4 \\
\hline Previous provided comments & $0.799^{* * *}$ & $0.797^{* * *}$ & $0.770^{* * *}$ & $0.778^{* * *}$ \\
\hline Previous initialized threads & 0.003 & 0.009 & $0.024^{* *}$ & $0.026^{* *}$ \\
\hline Has profile & $0.088^{* * *}$ & $0.086^{* * *}$ & $0.119^{* * *}$ & $0.118^{* * *}$ \\
\hline Tenure & $-0.051^{* * *}$ & $-0.053^{* * *}$ & $-0.187^{* * *}$ & $-0.284^{* * *}$ \\
\hline Maximum tenure & $0.256^{* * *}$ & $0.257^{* * *}$ & $0.425^{* * *}$ & $0.430^{* * *}$ \\
\hline Comments received & 0.002 & $-0.027^{* * *}$ & $-0.065^{* * *}$ & $-0.099^{* * *}$ \\
\hline Informational support received & & & $-0.044^{* * *}$ & $-0.048^{* * *}$ \\
\hline Emotional support received & & & $-0.018^{*}$ & -0.006 \\
\hline Comments received x Tenure & & $0.046^{* * *}$ & & $0.059^{* * *}$ \\
\hline Emormational support received x Tenure & & & & 0.007 \\
\hline Intercept & $0.044^{* * *}$ & $0.046^{* * *}$ & -0.025 & 0.035 \\
\hline Supported Hypotheses & Not H2 & $\mathrm{H} 3 \mathrm{~B}$ & Not H2 & $\mathrm{H} 3 \mathrm{~A} ; \mathrm{Not} \mathrm{H} 4$ \\
\hline
\end{tabular}

Table 4. Regression Coefficients of predicting the number of responses users provide to others. Here, p<0.001: $* * * ; \mathbf{p}<0.01 * * ; \mathbf{p}<0.05 *$. Number of users $=10,270$. Number of observations (user-month records) $=63,328$.

but not for those with less tenure. In contrast, receiving emotional support seems to decrease commitment for higher tenured members.

\section{DISCUSSION AND CONCLUSION}

This research examined how communication in an online cancer support community changes with members' tenure, and how communication members received predicted their subsequent commitment. Overall, our research confirms prior findings on how communication affects members' commitment $[2,17]$, and most importantly, it provides important new data regarding the impact of tenure on responses to communication. Table 5 summarizes the results. Through four analyses, we found that:

- The extent to which members sought informational and emotional support on the site declined with tenure. Although members initialized fewer threads in their first month on the site than they did subsequently, initiating threads declined with tenure after the first month. These results are consistent with $\mathrm{H} 1$, suggesting that seeking resources on the site was less important for users as they gained experience, either because people with short-term support needs dropped out of the community, motives for participating in the community changed with experience, or higher tenured users didn't need to probe the community to establish how well it fits their needs.

- Receiving comments from others was generally associated with increases in members' commitment to the community. However, receiving informational or emotional support in the comments was associated with declines in commitment.

- Receiving comments was generally associated with greater increases in members' commitment for higher tenured members in contrast to lower tenured ones. However, receiving informational or emotional support was associated with more commitment for lower tenured members than higher tenured members.

Although the results of Analysis 1 confirm H1, that community members' seeking behaviors declined significantly with tenure, the second part of $\mathrm{H} 1$ was not supported. Seeking informational support did not decline faster than seeking emotional support. Seeking informational and emotional support may decline at the same rate because these support needs change over the course of users' disease trajectory independent of participation in the site [32]. Most people join the site shortly after they or a loved one was diagnosed with cancer, when needs for both types of support needs are high [28]. Shortly after diagnosis, people need emotional support to help them deal with the uncertainty about their future and terms of their diagnosis. They also have more pragmatic concerns in understanding such topics as terminology, the nature of their diagnosis, choices among treatment, side effects, for which informational support is most helpful. However, both the stresses and informational needs associated with disease and treatment tend to decline with time $[32,3]$.

We had expected that receiving communication from others and the supportive nature of the communication would both increase people's commitment to the community. However, the empirical analyses show that while receiving communication was associated with increases in members' commitment, receiving informational or emotional support was associated with decreases. This contrast between the amount of communication and the kind of support contained in it suggests that the communication people receive on this site serves purposes beyond the exchange of informational or emotional support. For example, the communication may be crucial in building social relationships, which increases members' commitment to the site. Alternatively, the communication may provide members an opportunity to share their experiences, compare themselves with similar others or offer help to others. The need for other resources via communication might be longer term and require deeper interactions. Via communication, people who have shorter-term needs might have their immediate needs met easily, and thus have less reason to stay or value less the received social support, compared to people with longer term purposes. Indeed, the survey data show that with tenure people on the site increasingly use it to offer help to others. As one CSN participant stated in an interview that she now is "looking for people who are seeking for advice [to] offer 


\begin{tabular}{|c|c|c|c|c|c|c|}
\hline & Analysis 1 & Analysis 2 & \multicolumn{2}{|c|}{ Analysis 3} & \multicolumn{2}{|c|}{ Analysis 4} \\
\hline $\begin{array}{l}\text { Dependent } \\
\text { Variables }\end{array}$ & $\begin{array}{l}\text { Seeking } \\
\text { behaviors }\end{array}$ & $\begin{array}{c}\text { Self-reported } \\
\text { attachment }\end{array}$ & $\begin{array}{r}\text { Surviva } \\
\text { subsequer }\end{array}$ & $\begin{array}{l}\text { Length of } \\
\text { participation }\end{array}$ & $\begin{array}{r}\text { Response } \\
\text { to he }\end{array}$ & $\begin{array}{l}\text { Willingness } \\
\text { others }\end{array}$ \\
\hline $\begin{array}{l}\text { Independent } \\
\text { Variables }\end{array}$ & Tenure & $\begin{array}{l}\text { Tenure, } \\
\text { comments } \\
\text { received }\end{array}$ & $\begin{array}{c}\text { Tenure, } \\
\text { comments } \\
\text { received }\end{array}$ & $\begin{array}{c}\text { Tenure, info } \\
\text { and emo } \\
\text { support } \\
\text { received }\end{array}$ & $\begin{array}{c}\text { Tenure } \\
\text { comments } \\
\text { received }\end{array}$ & $\begin{array}{c}\text { Tenure, info } \\
\text { and emo } \\
\text { support } \\
\text { received }\end{array}$ \\
\hline H1: Newcomers seek more resources & $\boldsymbol{V}_{p}$ & - & - & - & - & - \\
\hline $\begin{array}{l}\text { H2: Communication and support } \\
\text { increase commitment }\end{array}$ & - & $\sqrt{ }$ & $\sqrt{ }$ & $x$ & $n s$ & $x$ \\
\hline $\begin{array}{l}\text { H3A: Communication increases } \\
\text { commitment more for newcomers }\end{array}$ & - & $n s$ & $x$ & $\sqrt{ }$ & $x$ & $\sqrt{ }$ \\
\hline $\begin{array}{l}\text { H3B:Communication increases } \\
\text { commitment more for old-timers }\end{array}$ & - & $n s$ & $\sqrt{ }$ & $x$ & $\sqrt{ }$ & $x$ \\
\hline $\begin{array}{l}\text { H4:The effect of informational and } \\
\text { emotional support vary with tenure }\end{array}$ & - & - & - & $x$ & - & $x$ \\
\hline
\end{tabular}

Table 5. Summary of analyses and hypotheses. Here, $\checkmark$ means Supported, $\checkmark_{p}$ means Partially supported, ns means Not supported, $X$ means Disconfirmed and - means Not applicable.

her help." Another noted that she initially stayed "because information was important at the time," but, over time, she found "talking with people who had the same experience is more helpful".

The results show that the amount and content of communication affect commitment differently for people with more or less experience on the site. Specially, receiving comments from others is associated with larger increases in commitment for members with more tenure. This result suggests communication in the community matches the needs of higher tenured members more than less experienced ones. This may be especially the case for longer term needs such as developing social relationships or providing help to others. Through conversation with others, old-timers can satisfy personal needs as well as influence the community, making it a more positive one that better fits their goals.

In contrast, receiving either informational or emotional support from the community was associated with larger increases in commitment (or smaller declines) for users with less tenure compared to those with more. This may occur because informational support and emotional support, which are the major reasons that people join health support groups [48, 35], fulfill the immediate needs that newcomers to a support group have. In addition, the principle of diminishing marginal utility suggests that receiving informational or emotional support should have a larger effect for less experienced members than for those with more tenure. Finally, receiving messages containing social support may also reduce newcomers' uncertainty about whether the group is a good fit. A CSN user stated that she gained lots of support immediately after asking many questions when she first joined, from which she felt this community is trustworthy and more helpful than other sites.

\section{Generalization}

Our work examined the effects of both the quantity and content of communication on commitment. Findings about quantity are applicable to online groups in general, not just support groups. We treated social support contained in messages as proxies for resources that group members exchange, and these findings may be applicable to a wide variety of support groups (e.g., parenting, autism, dieting, etc.), although measures of support might differ across these groups. We urge caution, however, for applying our findings to groups that exchange non-support resources (e.g., topical or friendships groups).

\section{Design Recommendation and Implication}

The most immediate practical conclusion from this research is that the needs of short-term and longer-term users of online communities differ and, therefore, resources that keep members committed change with their tenure. Online health communities need to present resources in ways that satisfy different needs that change with members' experience. For example, the diminishing return effect suggests that support groups can maintain the participation of higher-tenured members not by offering them more support, but by providing them with different experiences, such as opportunities to provide support to others.

\section{Limitations}

An important limitation of this research is its correlational nature. We used panel data and lagged dependent variable analyses to examine how the communication received in one time period predicted changes in commitment at a later period. This type of data and analysis mitigate many problems in inferring causation from correlational data [25, 7]. However, without true random-assignment experimentation we cannot assume that the relationships described in this paper reflect causation.

A second limitation is that our automated content analysis measured only informational and emotional support contained in messages. We need a broader set of content measures to explain why the amount of communication and its content had different relationships with commitment.

Finally, this study only considered users who have posting behaviors in the forum, and hence our findings might not be applicable to lurkers. Direct records about users' browsing and clicking logs would provide a finer-grained measure of how exposure to comments and different types of social support influence commitment. 


\section{REFERENCES}

1. Frederik Anseel, Adam S Beatty, Winny Shen, Filip Lievens, and Paul R Sackett. 2015. How are we doing after 30 years? A meta-analytic review of the antecedents and outcomes of feedback-seeking behavior. Journal of Management 41, 1 (2015), 318-348.

2. Jaime Arguello, Brian S Butler, Elisabeth Joyce, Robert Kraut, Kimberly S Ling, Carolyn Rosé, and Xiaoqing Wang. 2006. Talk to me: foundations for successful individual-group interactions in online communities. In Proceedings of the SIGCHI conference on Human Factors in computing systems. ACM, 959-968.

3. Jo Armes, Maggie Crowe, Lynne Colbourne, Helen Morgan, Trevor Murrells, Catherine Oakley, Nigel Palmer, Emma Ream, Annie Young, and Alison Richardson. 2009. Patients' supportive care needs beyond the end of cancer treatment: a prospective, longitudinal survey. Journal of Clinical Oncology 27, 36 (2009), 6172-6179.

4. Blake E Ashforth, David M Sluss, and Alan M Saks. 2007. Socialization tactics, proactive behavior, and newcomer learning: Integrating socialization models. Journal of Vocational Behavior 70, 3 (2007), 447-462.

5. Blake K Ashforth and Alan M Saks. 1996. Socialization tactics: Longitudinal effects on newcomer adjustment. Academy of Management Journal 39, 1 (1996), 149-178.

6. Antonina Bambina. 2007. Online social support: the interplay of social networks and computer-mediated communication. Cambridge Press.

7. Thomas S Bateman and Stephen Strasser. 1984. A longitudinal analysis of the antecedents of organizational commitment. Academy of Management Journal 27, 1 (1984), 95-112.

8. Talya N Bauer, Todd Bodner, Berrin Erdogan, Donald M Truxillo, and Jennifer S Tucker. 2007. Newcomer adjustment during organizational socialization: a meta-analytic review of antecedents, outcomes, and methods. Journal of Applied Psychology 92, 3 (2007), 707.

9. Prakhar Biyani, Cornelia Caragea, Prasenjit Mitra, and John Yen. 2014. Identifying Emotional and Informational Support in Online Health Communities.. In COLING. 827-836.

10. Robert D Caplan. 1987. Person-environment fit theory and organizations: Commensurate dimensions, time perspectives, and mechanisms. Journal of Vocational Behavior 31, 3 (1987), 248-267.

11. Wen-ying Sylvia Chou, Benmei Liu, Samantha Post, and Bradford Hesse. 2011. Health-related Internet use among cancer survivors: data from the Health Information National Trends Survey, 2003-2008. Journal of Cancer Survivorship 5, 3 (2011), 263-270.

12. Jacob Cohen, Patricia Cohen, Stephen G West, and Leona S Aiken. 2013. Applied multiple regression/correlation analysis for the behavioral sciences. Routledge.
13. Sheldon Cohen. 2004. Social relationships and health. American Psychologist 59, 8 (2004), 676.

14. Debra R Comer. 1991. Organizational newcomers' acquisition of information from peers. Management Communication Quarterly 5, 1 (1991), 64-89.

15. Nicole B Ellison, Charles Steinfield, and Cliff Lampe. 2011. Connection strategies: Social capital implications of Facebook-enabled communication practices. New Media \& Society (2011), 873-892.

16. Samer Faraj and Steven L Johnson. 2011. Network exchange patterns in online communities. Organization Science 22, 6 (2011), 1464-1480.

17. Rosta Farzan, Laura A. Dabbish, Robert E. Kraut, and Tom Postmes. 2011. Increasing Commitment to Online Communities by Designing for Social Presence. In Proceedings of the ACM 2011 Conference on Computer Supported Cooperative Work (CSCW'11). ACM, New York, NY, USA, 321-330.

18. Kathryn Greene, Valerian J Derlega, and Alicia Mathews. 2006. Self-disclosure in personal relationships. The Cambridge Handbook of Personal Relationships (2006), 409-427.

19. Jamie A Gruman, Alan M Saks, and David I Zweig. 2006. Organizational socialization tactics and newcomer proactive behaviors: An integrative study. Journal of Vocational Behavior 69, 1 (2006), 90-104.

20. Lisa K Gundry. 1993. Fitting into technical organizations: The socialization of newcomer engineers. IEEE Transactions on Engineering Management 40, 4 (1993), 335-345.

21. Aaron Halfaker, R Stuart Geiger, Jonathan T Morgan, and John Riedl. 2012. The rise and decline of an open collaboration system: How Wikipedia's reaction to popularity is causing its decline. American Behavioral Scientist (2012), 0002764212469365.

22. David Huffaker. 2010. Dimensions of leadership and social influence in online communities. Human Communication Research 36, 4 (2010), 593-617.

23. Mary C Johannesen-Schmidt and Alice H Eagly. 2002. Diminishing returns: The effects of income on the content of stereotypes of wage earners. Personality and Social Psychology Bulletin 28, 11 (2002), 1538-1545.

24. Emil Kauder. 2015. History of Marginal Utility Theory. Princeton University Press (2015).

25. Luke Keele and Nathan J Kelly. 2006. Dynamic models for dynamic theories: The ins and outs of lagged dependent variables. Political Analysis 14, 2 (2006), 186-205.

26. Amy Jo Kim. 2000. Community building on the web: Secret strategies for successful online communities. Addison-Wesley Longman Publishing Co., Inc. 
27. Robert Kraut, Moira Burke, John Riedl, and P Resnick. 2012. The challenges of dealing with newcomers. Building successful online communities: Evidence-based social design 1 (2012), 179-230.

28. Sophie Lebel, Zeev Rosberger, Linda Edgar, and Gerald M Devins. 2007. Comparison of four common stressors across the breast cancer trajectory. Journal of Psychosomatic Research 63, 3 (2007), 225-232.

29. Denis MS Lee and Thomas J Allen. 1982. Integrating new technical staff: Implications for acquiring new technology. Management Science 28, 12 (1982), $1405-1420$.

30. Jeffrey A LePine, Amir Erez, and Diane E Johnson. 2002. The nature and dimensionality of organizational citizenship behavior: a critical review and meta-analysis. Journal of Applied Psychology 87, 1 (2002), 52.

31. John M Levine and Richard L Moreland. 1994. Group socialization: Theory and research. European Review of Social Psychology 5, 1 (1994), 305-336.

32. Michelle Elizabeth McDowell, Stefano Occhipinti, M Ferguson, Jeffrey Dunn, and SK Chambers. 2010. Predictors of change in unmet supportive care needs in cancer. Psycho-Oncology 19, 5 (2010), 508-516.

33. M Ann McFadyen and Albert A Cannella. 2004. Social capital and knowledge creation: Diminishing returns of the number and strength of exchange relationships. Academy of Management Journal 47, 5 (2004), 735-746.

34. Katelyn YA McKenna, Amie S Green, and Marci EJ Gleason. 2002. Relationship formation on the Internet: What's the big attraction? Journal of Social Issues 58, 1 (2002), 9-31.

35. Andrea Meier, Elizabeth J Lyons, Gilles Frydman, Michael Forlenza, and Barbara K Rimer. 2007. How cancer survivors provide support on cancer-related Internet mailing lists. J Med Internet Res 9, 2 (2007), e12.

36. Vernon D Miller and Fredric M Jablin. 1991. Information seeking during organizational entry: Influences, tactics, and a model of the process. Academy of Management Review 16, 1 (1991), 92-120.

37. Elizabeth Wolfe Morrison. 2002. Information seeking within organizations. Human Communication Research 28, 2 (2002), 229-242.

38. Richard T Mowday, Richard M Steers, and Lyman W Porter. 1979. The measurement of organizational commitment. Journal of Vocational Behavior 14, 2 (1979), 224-247.

39. Katherine Panciera, Aaron Halfaker, and Loren Terveen. 2009. Wikipedians Are Born, Not Made: A Study of Power Editors on Wikipedia. In Proceedings of the ACM 2009 International Conference on Supporting Group Work (GROUP '09). ACM, New York, NY, USA, 51-60.
40. Katherine Panciera, Reid Priedhorsky, Thomas Erickson, and Loren Terveen. 2010. Lurking? cyclopaths?: a quantitative lifecycle analysis of user behavior in a geowiki. In Proceedings of the SIGCHI Conference on Human Factors in Computing Systems. ACM, 1917-1926.

41. Jenny Preece, Blair Nonnecke, and Dorine Andrews. 2004. The top five reasons for lurking: improving community experiences for everyone. Computers in Human Behavior 20, 2 (2004), 201-223.

42. Jennifer Preece and Ben Shneiderman. 2009. The reader-to-leader framework: Motivating technology-mediated social participation. AIS Transactions on Human-Computer Interaction 1, 1 (2009), 13-32.

43. Deborah A Prentice, Dale T Miller, and Jenifer R Lightdale. 1994. Asymmetries in attachments to groups and to their members: Distinguishing between common-identity and common-bond groups. Personality \& Social Psychology Bulletin 20, 5 (1994).

44. Yuqing Ren, F Maxwell Harper, Sara Drenner, Loren Terveen, Sara Kiesler, John Riedl, and R Kraut. 2012. Increasing attachment to online communities: Evidence-based design. MIS Quarterly 36, 3 (2012), 841-864.

45. Yuqing Ren, Robert Kraut, and Sara Kiesler. 2007. Applying common identity and bond theory to design of online communities. Organization Studies 28, 3 (2007), 377-408.

46. Catherine M Ridings and David Gefen. 2004. Virtual community attraction: Why people hang out online. Journal of Computer-Mediated Communication 10, 1 (2004), 00-00.

47. Barbara K Rimer, Elizabeth J Lyons, Kurt M Ribisl, J Michael Bowling, Carol E Golin, Michael J Forlenza, and Andrea Meier. 2005. How new subscribers use cancer-related online mailing lists. Journal of Medical Internet Research 7, 3 (2005), e32.

48. Shelly Rodgers and Qimei Chen. 2005. Internet community group participation: Psychosocial benefits for women with breast cancer. Journal of Computer-Mediated Communication 10, 4 (2005), 00-00.

49. Keith Rollag. 2004. The impact of relative tenure on newcomer socialization dynamics. Journal of Organizational Behavior 25, 7 (2004), 853-872.

50. Alan Saks and Jamie A. Gruman. 2014. Making organizations more effective through organizational socialization. Journal of Organizational Effectiveness: People and Performance 1, 3 (2014), 261-280.

51. Kai Sassenberg. 2002. Common bond and common identity groups on the Internet: Attachment and normative behavior in on-topic and off-topic chats. Group Dynamics: Theory, Research, and Practice 6, 1 (2002), 27. 
52. Benjamin Schneider, D Brent Smith, and Harold W Goldstein. 2000. Attraction-selection-attrition: Toward a person-environment psychology of organizations. Lawrence Erlbaum Associates Publishers.

53. Bret R Shaw, Fiona McTavish, Robert Hawkins, David H Gustafson, and Suzanne Pingree. 2000. Experiences of women with breast cancer: exchanging social support over the CHESS computer network. Journal of Health Communication 5, 2 (2000), 135-159.

54. Mel Slater, Amela Sadagic, Martin Usoh, and Ralph Schroeder. 2000. Small-group behavior in a virtual and real environment: A comparative study. Presence 9, 1 (2000), 37-51.

55. LP StataCorp and others. 2007. Stata data analysis and statistical Software. Special Edition Release 10 (2007).

56. Yla R Tausczik, Laura A Dabbish, and Robert E Kraut. 2014. Building loyalty to online communities through bond and identity-based attachment to sub-groups. In Proceedings of the 17th ACM conference on Computer supported cooperative work \& social computing. ACM, 146-157.

57. Tatiana A Vlahovic, Yi-Chia Wang, Robert E Kraut, and John M Levine. 2014. Support matching and satisfaction in an online breast cancer support community. In Proceedings of the SIGCHI Conference on Human Factors in Computing Systems. ACM, 1625-1634.

58. Yi-Chia Wang, Robert Kraut, and John M Levine. 2012. To stay or leave?: the relationship of emotional and informational support to commitment in online health support groups. In Proceedings of the ACM 2012 conference on Computer Supported Cooperative Work. ACM, 833-842.

59. Yi-Chia Wang, Robert E Kraut, and John M Levine. 2015. Eliciting and receiving online support: using computer-aided content analysis to examine the dynamics of online social support. Journal of Medical Internet Research 17, 4 (2015), e99.

60. Joseph Weizenbaum. 1966. ELIZA - a computer program for the study of natural language communication between man and machine. Commun. ACM 9, 1 (1966), 36-45.

61. Haiyi Zhu, Robert Kraut, and Aniket Kittur. 2012. Effectiveness of shared leadership in online communities. In Proceedings of the ACM 2012 conference on Computer Supported Cooperative Work. ACM, 407-416. 